Differences in personality / temperament in the endangered tortoise Testudo hermanni and their implications on dispersal and conservation

4 Alexandra Rodriguez ${ }^{1, *}$, Sébastien Caron $^{1}$, Jean Marie Ballouard ${ }^{1}$

5

$6 \quad{ }^{1}$ CRCC Centre for Research and Conservation of Chelonians, SOPTOM, Var, 83660

7 Carnoules FRANCE,

8 France. Tel: +33 (0)4 947828 93. Email: rodrialexandra@ gmail.com

9 *Corresponding author: Alexandra Rodríguez

10 


\section{Rodriguez et al.}

\section{ABSTACT}

12 Behavioural studies are more an more implicated in species conservation. Determining

13 individuals personality in the case of reintroduction operations may be very useful. Actually,

14 indiviuals temperament may be associated to their dispersal capacities and their habilities to

15 adapt to novel environments. Considered as asociable species, few studies have been

16 conducted on reptiles and this is even worse in the case of endangered species. Hermann

17 tortoise, Testudo hermanni, an endemic species from Mediterranean region is endangered

18 because of the lost and modification of its habitats. Before conducting reintroduction actions

19 it is important to have more information on individuals personality traits. We have tested the

20 reaction of three groups of tortoises (domestic, wild and from the SOPTOM center) when

21 confronted to a novel environment and to human presence. The aim was to discriminate

22 individuals with « bold» and «shy » behaviours. Behavioural profiles are different between

23 the three groups of tortoises, the domestic group appeared to be bolder than the wild one.

24 Moreover, for the wild group, bold individuals travel longer distances in the field, sometimes

25 outside the protected areas. Thus, it is important to take into account the personality of

26 individuals choosen for translocation projects.

28 Keywords: personality, dispersal, tortoises, conservation, exploration,

29 antipredatory-behaviour

\section{Introduction}

31 Translocations are methods more and more used in wildlife management. They consist in

32 moving animals from one location to another and they are more and more implemented in

33 conservation programs during the last decades. They are increasingly applied as a form of 


\section{Rodriguez et al.}

34 mitigation for endangered species (Germano et al. 2015; Sullivan et al. 2015) and they need to

35 be carefully prepared to optimize the choose of individuals that have more chance to survive

36 in the new places where they are released.

37 In this context taking into account factors as physiology and behavior becomes more and

38 more important when selecting the individuals and this is particularly true in the case of

39 reptiles' personality (Germano et al. 2017).

40 The terms personality and temperament indicate the interindividual differences in the

41 expression of the behavior present early in invididuals' lives and stable across the time and

42 contexts (Jones 1977, Bates 1989, Goldsmith et al. 1987, Sih et al. 2004).

43 Temperament and personality can be explored by the study of different behavioral

44 characteristics as sociability, activity, reactivity and emotivity in social, predatory and novel

45 situations (Bates 1986). These behavioral characteristics may condition dispersal behavior,

46 approach towards novel objects and novel food items consumption (Sinn et al. 2008).

47 Thereby, in non-human animals those aspects of behavior may constraint individuals'

48 travelled distances and home ranges characteristics (Digemanse et al. 2002, Van Oers et al.

49 2004a). According to several studies conducted in humans, the differences observed in

50 temperament would have genetic and physiologic bases (Emde et al. 1992, Plomin et al. 1993,

51 Groothuis and Carere 2005) and would be modulated by the individuals' experience, which

52 generates personality. When suites of correlated bahaviours are expressed across the contexts,

53 we talk about syndromes or coping styles (Wechsler 1995, Sih et al. 2004).

54 In personality literature individuals have been classified as bold or shy depending on the 55 degree of exploratory behaviour's they express.

56 Few studies have been conducted on reptiles, however, differences in temperament have been 
57 observed in lizards for example and these differences appeared as being involved in learning

58 processes (Carazo et al. 2014). Actually, in this case, bold individuals appeared to learn faster

59 than shy ones because of their tendency to explore earlier the objects and the experimental

60 apparatus. In the Namibian rock agama, Agama planiceps, it has been demonstrated that bold

61 individuals are more easily trapped than shy ones (Carter et al. 2012)

62 Hermann tortoise, Testudo hermanni, is an endangered tortoise only present in the

63 Mediterranean region and its geographic distribution has been declining during the last

64 decades as a consequence of modifications in landscape use and structure (Livoreil 2009).

65 Studies on animal personality have been conducted on common, domestic and invasive

66 species (Jones 1977a, Dingemanse et al 2005, Rodriguez 2010, Martin et Fitzgerald 2005) but

67 not on endangered ones. More information is necessary to understand habitat use by those

68 species and exploration of personality traits as exploration of novel environments or

69 antipredatory reactions may be useful in conservation strategies.

70 The Village des Tortues Center offers the possibility to study Testudo hermanni behavior and

71 to compare three different groups with different past experiences. There are almost wild

72 individuals (manipulated very few times), very wild ones, and 'domestic' individuals very

73 often manipulated by technicians and with a frequent human as Village visitors come to see

74 them.

75 We tested novel environment explorative behavior and antipredatory reactions, and we

76 hypothesized that reactions in the tests would differ depending on the individuals' past

77 experience. We wondered if there would be a correlation between the novel environment

78 behaviors and the antipredatory reactions.

79 We conducted tests in order to compare personality between males and females and between 
80 'wild' and 'domestic' individuals. We also tested for the temporal repeatability of the

81 behavioral responses when individuals were confronted two or four times with the novel

82 environment. We classified individuals as bold or shy and characterized these profiles. Finally,

83 for the wild group we measured the distances traveled by the individuals in the nature in order

84 to know if there was a difference in dispersal behavior between bold and shy individuals.

\section{Methods}

\section{Preliminary experiments}

88 We observed four Hermann tortoises in a novel environment test during $1 \mathrm{~h}$ in order to define

89 the duration of the study experiments and to identify all the behavioral items that can be

90 observed during this kind of test. We video recorded the preliminary test and all the

91 subsequent experiments with a Canon Power Shot SD A2500 camera. We classified the

92 behaviors in four categories: walk, immobility, visual exploration, olfactive exploration (Table

93 1). We paid particular attention to visual and olfactive exploration as it has been demonstrated

94 that visual attention in important in novel situations in Testudo Hermanni (Chrzanowska et al.

95 2015).

96 Table 1

\section{Observed behaviors}

\begin{tabular}{ll}
\hline Behaviors & Category \\
\hline Walks forward (number of steps) & Walk \\
\hline Walks backward (number of steps) & Walk \\
\hline Walks turning (number of steps) & Walk \\
\hline Immobility (time while tortoise is immobile) & Immobility \\
\hline Raises head and visual fixation (number of times) & Visual exploration \\
\hline Turns head and visual fixation (number of times) & Visual exploration \\
\hline Visual fixation (number of times) & Visual exploration \\
\hline Smells the bottom of the box (number of times) & Olfactive exploration \\
\hline Smells the sidewalls of the box (number of times) & Olfactive exploration \\
\hline
\end{tabular}


Rodriguez et al.

99 We used a red box with a red bottom in order to put Hermann tortoises in a very new context

100 (there were used to be in green boxes or in nature with green and brown colours). It has been

101 demonstrated that they can distinguish these colours (Pelliteri-Rosa, 2010).

102

103 Novel environment test (neophobia test)

104 Studying the tortoises' behaviors in the $1 \mathrm{~h}$ experiment we concluded that 10 minutes of 105 observation were enough to visualize interindividual differences in exploration behavior, by 106 consequence we conducted 10 minutes duration neophobia tests.

107 The experimental apparatus was a box of dimensions $80 \mathrm{~cm} \times 100 \mathrm{~cm}$ and was divided into 12 108 cells of $26,5 \mathrm{~cm} \times 25 \mathrm{~cm}$

109 At the beginning of the experiment the tortoise was put under a hiding place which consisted 110 in a grey plastic tunnel of dimensions $25 \mathrm{~cm} \times 25 \mathrm{~cm}$ that covers the whole body of the tortoise

111 (Figure 1)

\section{Figure 1: Aparatus, red wood box}

\section{Novel environment}

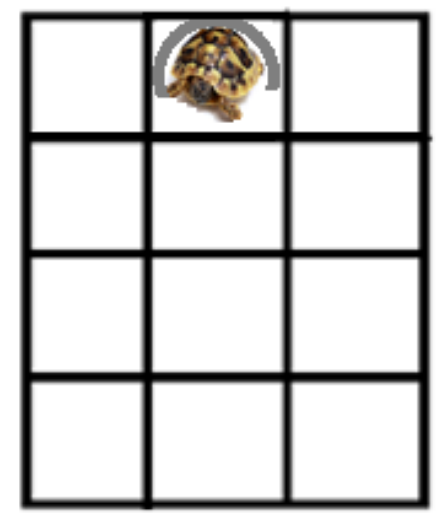

113

114 During the experiments we measured the time the tortoises took to exit the tunnel, the number 
115 of cells they visited ( 0 to 11$)$ and we counted all the behaviors they expressed.

116 At the end of the experiment we cleaned the box in order to avoid potential effects of olfactive

117 cues on the next individuals tested.

118 As we had measured the time of immobility and some tortoises went back into the tunnel we

119 divided the number of times the tortoises walked by the remaining time in the box outside the 120 tunnel and obtained the number of steps by minute:

121 Number of steps/min $=\quad$ Total number of steps

Test duration-(Time into the tunnel+Immobility duration)

124 Three groups with different life experiences were tested:

125 - the Tortoise Village Group: 13 males and 13 females that have been raised by years at

126 the Tortoise Village Center (they are tortoises that have been brought by people who

127 cannot take care of them anymore or who found them on the road)

128 - the Chelonian Conservation Center Group: 12 males and 9 females that have been

129 found in nature and brought to the center and who stay a short period in an isolated

$130 \quad$ area not disturbed by public

131 - the Wild Field Group: 8 males and 13 females that live in wild conditions and that 132 were tested in their natural field conditions.

137 where the tortoise was found by telemetry.

138 We conducted Mann Whitney tests in each group in order to know if there were 
139 differences in behavior between males and females for each behavioral category.

140 We conducted Kruskal-Wallis tests and paired Mann Whitney tests between the three groups

141 in order to know if they behave differently.

\section{Personalities}

144 Individuals were grouped into two categories. Individuals that visited less than half of the

145 cells ( 0 to 5 cells) were classified as shy (low explorers) and individuals that visited more than

146 half of the apparatus cells (6 to 11 cells) were classified as bold (high explorers).

147 The box test was repeated two times for the tortoises of the conservation center group and the

148 wild field group and it was repeated four times for the tortoise village group in order to see if

149 the tortoises' reactions were stable during time.

150 Tortoises were tested between 28/08/2015 and 10/09/2015 the first year and between

151 17/05/2016 and 24/05/2016 the second year. We choose those periods because temperature is

152 higher and general activity of the Hermann's tortoises is higher in this period and they all

153 have finished their hibernation period. We had to concentrate in periods of the year when

154 climate is similar and in sunny days while there was no rain and wind in order to avoid big

155 differences in climate conditions between the tests.

\section{Antipredator reaction}

158 Before the experiment in the box, the observer took the tortoise from its enclosure or from the 159 field and noted its antipredator reaction. Tortoises expressed three kinds of reactions in this

160 situation: retraction into the shell, nothing (the tortoise stays relaxed with the head and the 161 legs outside the shell) or struggles (the tortoise moves her head and legs and tries to separate 
Rodriguez et al.

162 from the experimenter)

163 Chi square tests were conducted in order to see if there was a relation between the bold/shy

164 individuals' reaction in the neophobia test and the antipredatory test.

\section{Effect of personalities on wild exploration and dispersion}

167 In previous studies of the team, the habitat use and home range of the wild Hermann Tortoises

168 was analyzed (Sibeaux et al. 2016, Pille et al. 2017). Telemetric monitoring allowed us to

169 measure the distances travelled by tortoises in the field during the days of monitoring over

170 two periods in 2013 and 2014.

171 Tortoises were fitted with an AVM-K16 transmitter glued onto the shell. The transmitter plus

172 resin represented $<10 \%$ of individual body mass, a value assumed to be well tolerated in free-

173 ranging tortoises (Lagarde et al., 2008). Each individual was located once a day, alternatively

174 in the morning, around midday and in the afternoon. Coordinates were recorded using a

175 Garmin GPS. Daily displacements of radio-tracked tortoises were calculated as the mean

176 distance travelled per day.

17719 tortoises (12 females and 7 males) of the wild field group described before were monitored

178 by this way. We used the GPS coordinates obtained each day to compute the distances

179 travelled by the tortoises.

180 We conducted Mann-Withney tests in order to know if there was a relation between the

181 behavioral profile of the individual in the neophobia test and the day distances they travelled.

\section{Results}

184 Differences of behavior in the neophobia test 
185 The comparison between the sexes in each group tested showed no differences for the 186 different behaviors studied (Mann Whitney test $\mathrm{p}>0.05$ for all the comparisons between

187 sexes). By consequence, we could regroup females and males of each group for the following 188 tests.

189 When we compared the three groups, we obtained differences in the expression of several 190 behaviors (Figure 2). Tortoises from the Chelonian Research Center and from the Wild Field 191 took significantly more time to exit the tunnel than the individuals from the Tortoise Village. 192 Those tortoises explored significantly less squares in the experimental dispositive and stayed 193 significantly more time in immobility than the tortoises from the Village.

194 During the exploration period, tortoises from the Field and from the Village elicit significantly 195 more deambulation movements than the tortoises from the Chelonian Research Center. 196 Tortoises from the Chelonian Research Center realized significantly more visual exploration 197 of the dispositive than the tortoises from the Wild Field and from the Village. They were no 198 differences in olfactive exploration between the three groups.

\section{Figure 2}



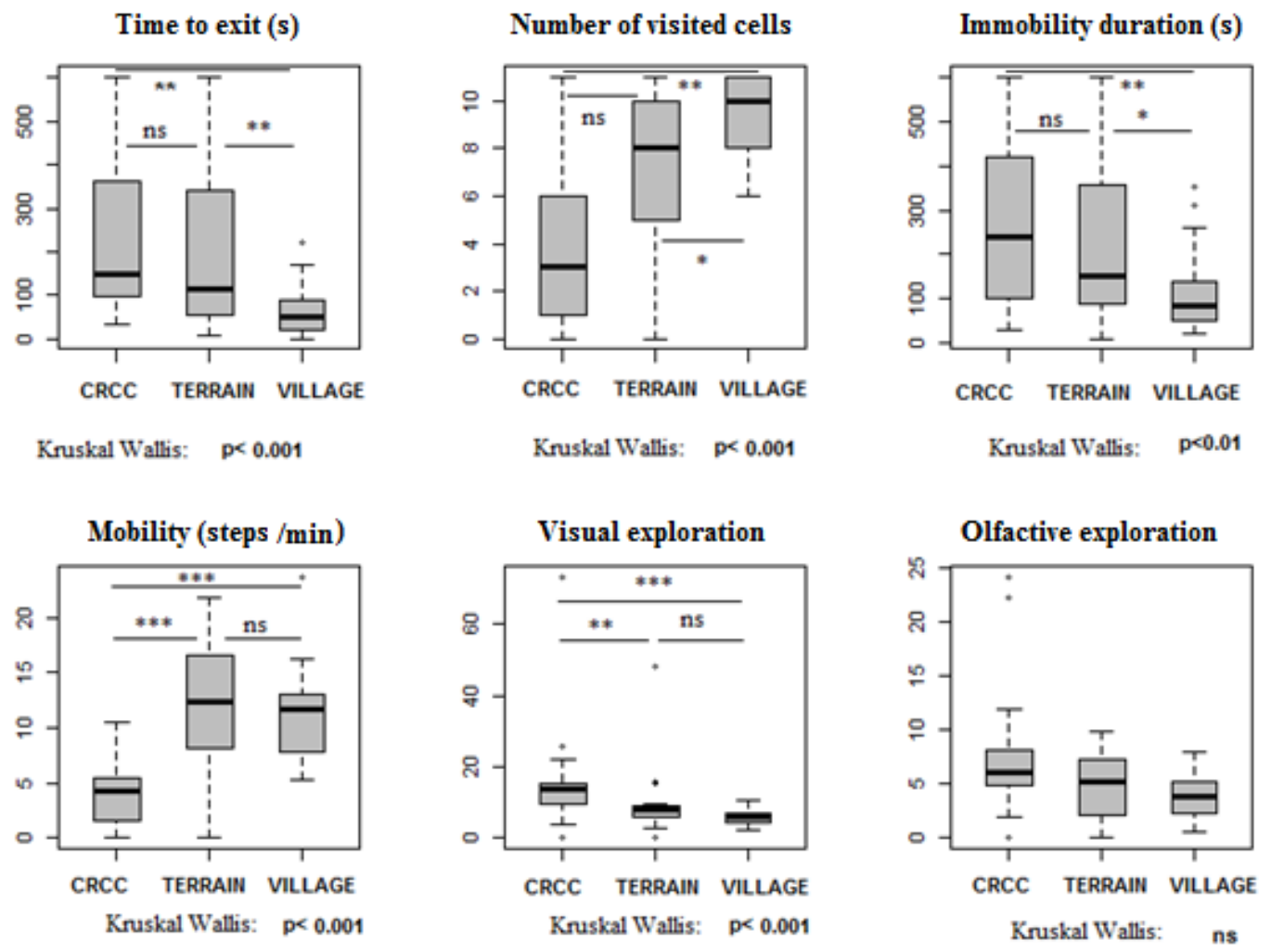

$$
\begin{aligned}
& \text { Mann Whitney tests: } \quad * \text { : } p<0.05 \\
& * *: \mathrm{p}<0.01 \\
& * * *: \mathrm{p}<0.001
\end{aligned}
$$

\section{CRCC=Chelonian Research Center Terrain=Wild field Village=Tortoise Village}

\section{Interindividual differences and personality}

206 When we took all the data (the three groups in neophobia test and tests repetitions) and

207 classified individuals into the bold ( 6 to 11 visited cells) and the shy ( 0 to 5 visited cells)

208 categories we obtained different behavioral profiles (Figure 3). Bold individuals show

209 significantly less time than the shy ones to exit the tunnel and they were significantly more

210 mobile than the shy ones. Shy individuals tended to explore more the experimental dispositive 
211 in a visual way than bold ones $(\mathrm{p}=0,06)$ while bold individuals explored significantly more by

212 olfactive exploration than shy ones $(\mathrm{p}=0.017)$.

\section{Figure 3: Behavioral characteristics of shy and bold individuals}
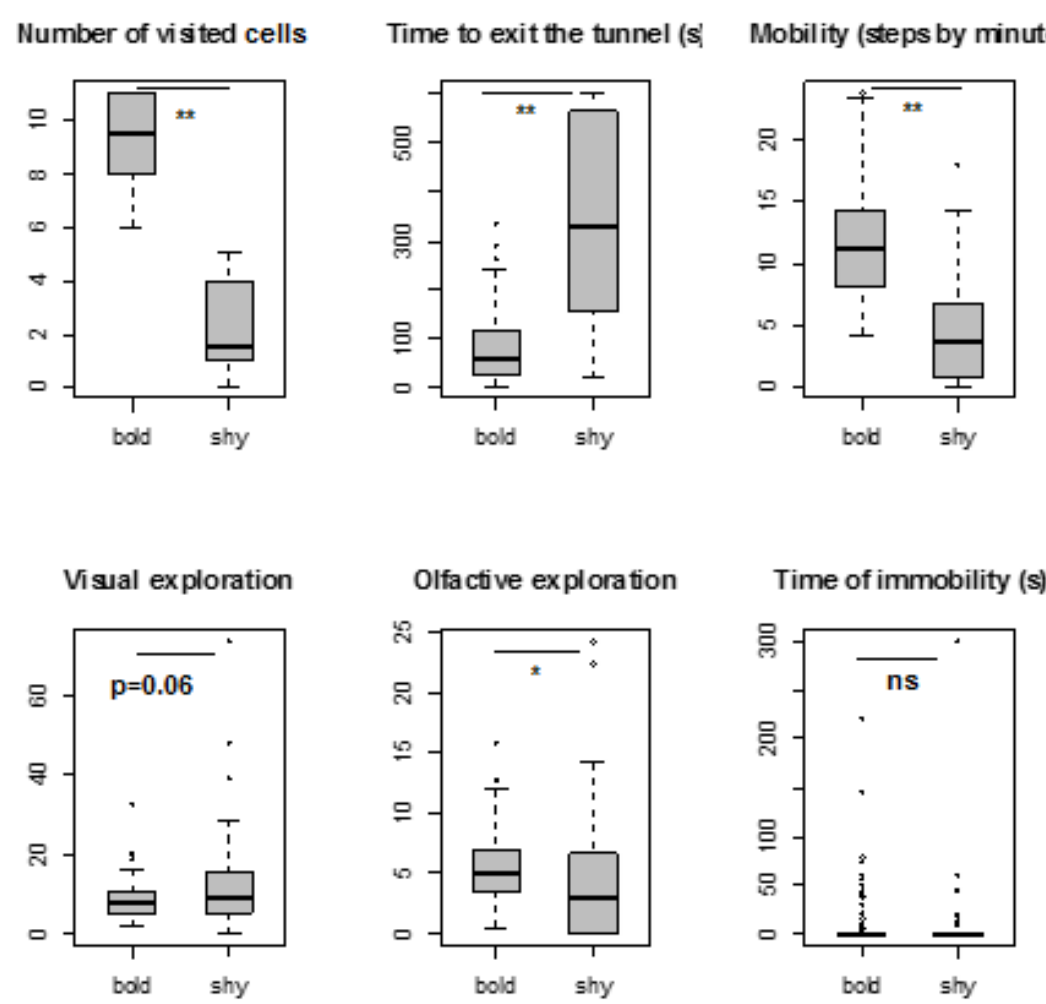

\section{4}

$\begin{aligned} \text { Mann Whitney tests: } \quad *: & \mathrm{p}<0.05 \\ * * & : \mathrm{p}<0.01 \\ * * * & : \mathrm{p}<0.001\end{aligned}$

\section{5}

\section{Repeatability of explorative behavior}

$21773,1 \%$ of the individuals behaved in the same way in the neophobia test and the repetition

218 test. $26,9 \%$ of the individuals behave one time shy and one time bold. Chi square test

219 conducted to a $\mathrm{p}$ value inferior to 0.01 indicating that individuals behave significantly more

220 frequently in the same way (Figure 4a). However, half of the individuals that presented both

221 behavioral profiles behave first in a shy way and then in a bold way, by consequence we can 
222 think that neophobia decreased in some individuals and conducted to a habituation of the

223 apparatus.

224 In the case of the individuals from the Tortoises' Village who were tested four times, $92 \%$ of

225 the individuals behave 3 or 4 times in the same way and $8 \%$ of the individuals behave twice

226 bold and twice shy (Figure $4 \mathrm{~b}$ ). Chi square value (Chi=4.4, $\mathrm{p}=0.035$ ) indicated that the

227 observed proportions were significantly different from the proportions expected by hazard.

228 This result also argues for a stability in the behavioral profiles.

229

230 Figure 4: Behavior stability in the neophobia and repetition tests

4.a

Individuals' behavior in the neophobia and the repetition test $(n=67)$

Individuals who behaved differently

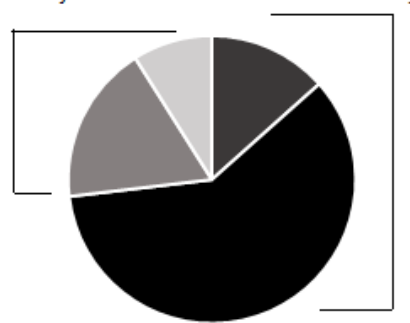

- shy-shy "bold-bold | shy-bold "b bold-shy

Chi square $=20.43 \quad p<0.01$ 4.b.

Behavior of the Village individuals in the four successive tests $(n=25)$

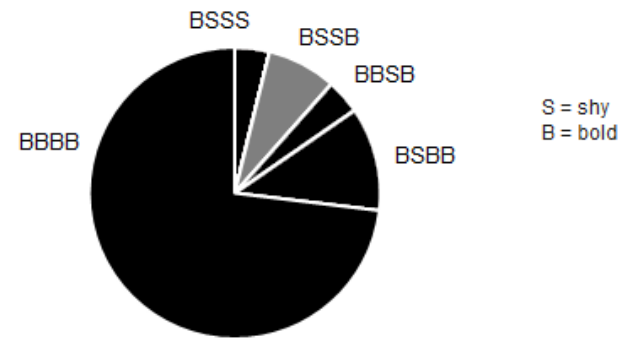

Individuals who behave in the same way 3 or 4 times

Individuals who behave two times bold and two times shy

Chi square $=4.4 \quad p=0.035$

Antipredator reaction

235 We compared antipredatory reactions between males and females and obtained no differences

236 (Figure 5a, Chi square $=5.41, \mathrm{p}=0.067$ ). 
237 Concerning the comparison between different boldness types, when the tortoises were taken

238 by the observer, only the individuals that behave in a bold way in the box struggled in the

239 hand of the observer (Figure 5b). There were significantly more shy individuals in the relaxed

240 group that did nothing and in the group that retracted into the shell than in the group that

241 struggled. These observations indicates that nothing reaction and retraction are behaviors

242 common to shy and bold individuals whereas struggle behavior is specific to bold individuals.

\section{Figure 5: a. Antipredator behaviors and sex}

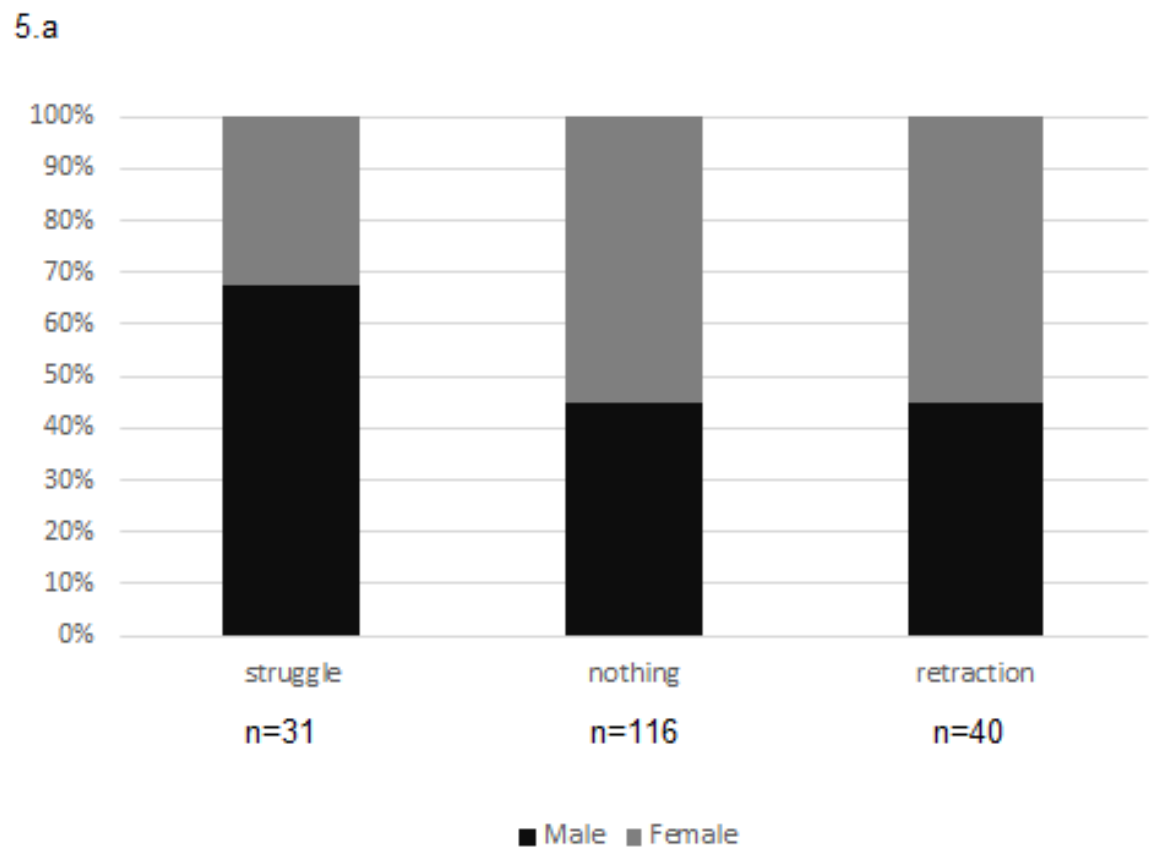

Chi square test Chi $=5.41 \quad p=0.067$ 


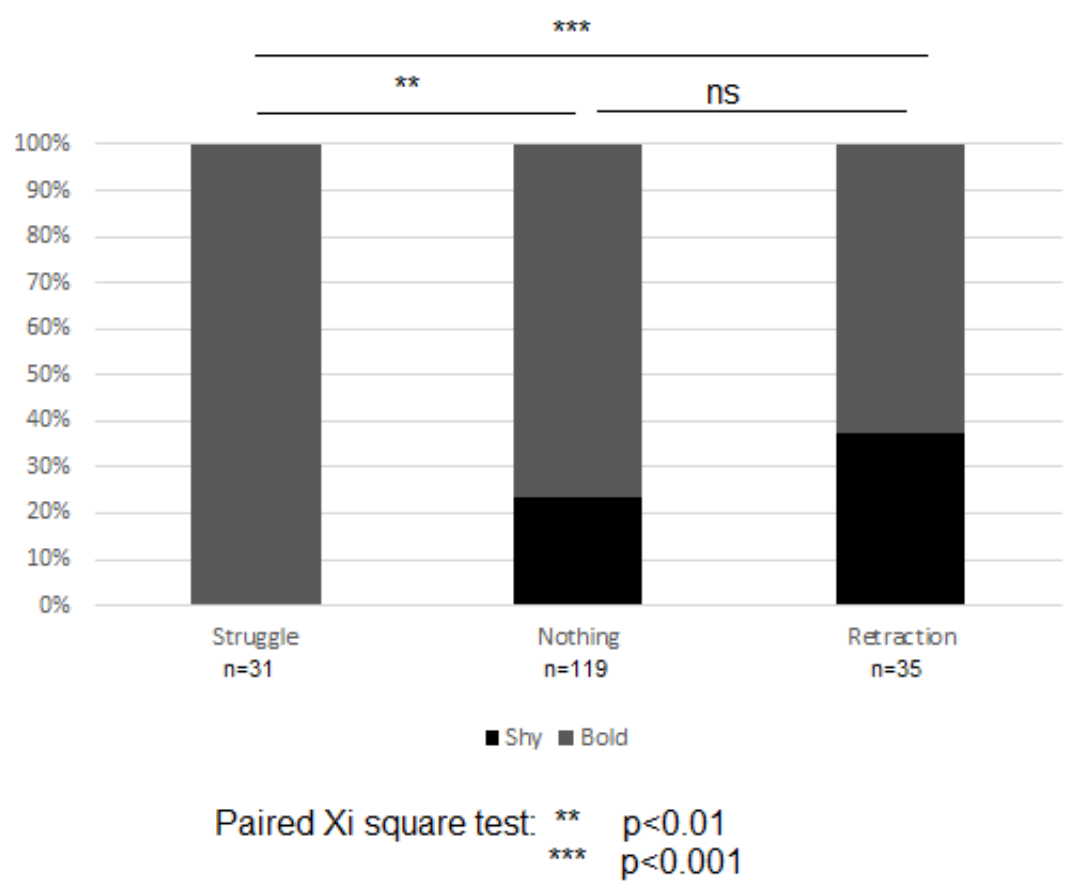

248 c. Antipredatory behaviors and frequency of contact with humans

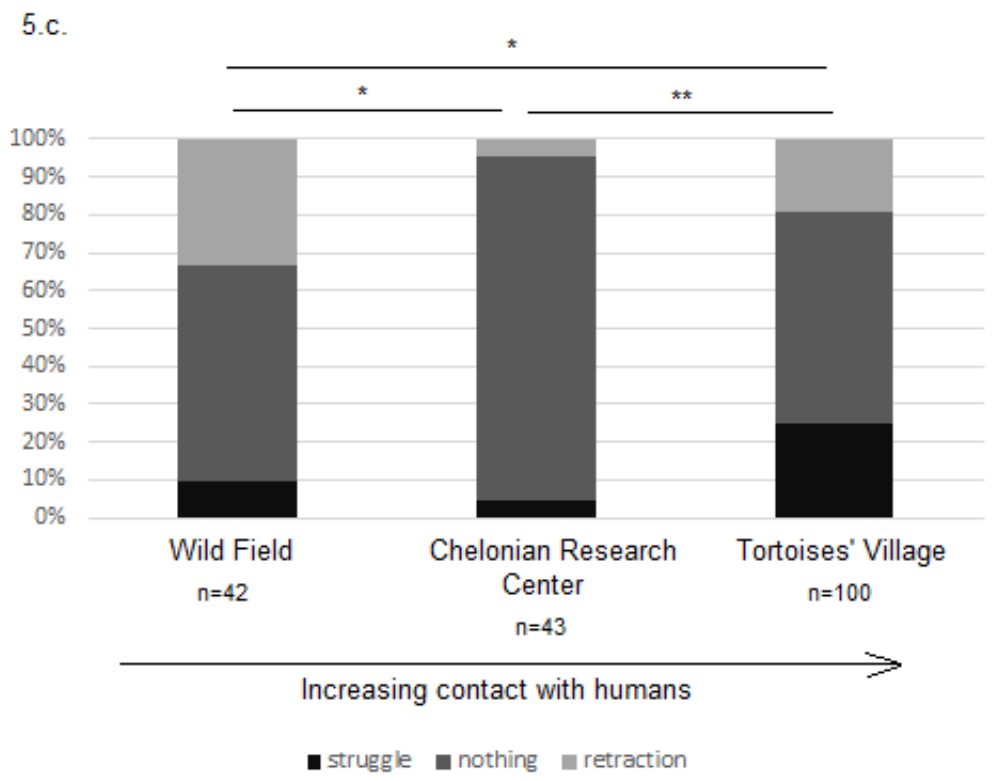



There were significant differences in antipredatory behavior between the groups with

252 different histories and contact with humans. Individuals from the Tortoise Village struggled

253 significantly more often than individuals from the Wild Field and from the Chelonian

254 Research Center. Wild Field tortoises retracted significantly more than tortoises that are used

255 to be manipulated by humans. Tortoises that have intermediate levels of manipulation

256 (Chelonian Research Center group) presented significantly more often the intermediate

257 relaxed antipredator reaction i.e. nothing.

259 Neophobia and dispersion

260 Individuals that were shy in the neophobia test travelled daily distances significantly shorter

261 than bold individuals (Figure 6, p <0.01). However there were no differences in the areas of 262 the home ranges between these two groups (Figure 7b, $\mathrm{p}=0.73$ )

264 Figure 7: a. Daily distances traveled in 2013 and 2014 by bold and shy individuals. 

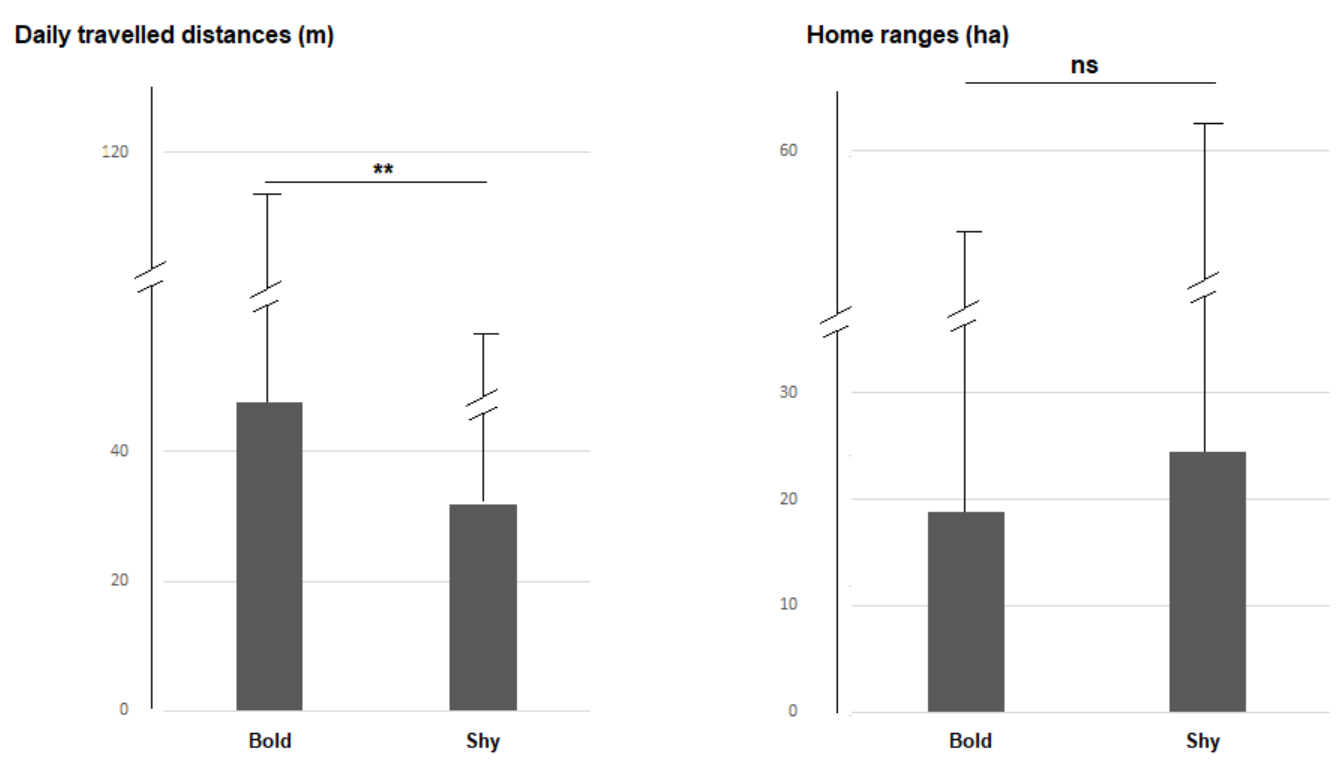

\section{References:}

271
Bates, JE. 1986.The measurement of temperament. In Plomin, R. \& Dunn, J. (Eds.), The study of temperament: Changes, continuities and challenges (pp.1-11). Hillsdale, NJ: Lawrence Erlbaum.

Bates, J. E. (1989). Concepts and measures of temperament. In G. A. Kohnstamm, J. E. Bates, \& M. K. Rothbart (Eds.), Temperament in childhood (pp. 3-26). Oxford, England: John Wiley \& Sons.

Berry, KH. 1986. Desert tortoise (Gopherus agassizi) relocation: implications of social behavior and movements. Herpetologica 42: 113-125

Bonnet X, Fizesan A, Michel CL. 2013. Shelter availability, stress level and digestive performance in the aspic viper. Journal of Experimental Biology 216: 815-822

Bonnet X, El Hassani MS, Lecq S, Michel CL, El Mouden EH, Michaud B, Slimani T. 2016. Blood mixtures: impact of puncture site on blood parameters. Journal of Comparative Physiology B 186: 787-800 
291 Carazo P, Noble D, Chandrasoma D, Whiting MJ. 2014. Sex and boldness explain individual 292 differences in spatial learning in a lizard. Proceedings of the Royal Society 281 (1782):

293

294

295

296

297

298

299

300

301

302

303

304

305

306

307

308

309

310

311

312

313

314

315

316

317

318

319

320

321

322

323

324

325

326

327

328

329

330

331

332

333

334

335

336
Carter J, Heinsohn R, Goldizen A, Biro P. 2012. Boldness, trappability and sampling bias in wild lizards. Animal Behaviour 83 (4): 1051-1058

Chrzanowska A, Modlinska K, Stryjek R, Pisula W. 2015. Response to Perceptual Novelty in Tortoises-A Preliminary Study. Journal of Biology and Life Science 7 (1): 12-18

Dingemanse N, Réale D. 2005. Natural selection and animal personality. Behaviour 142: $1165-1190$

Drake KK, Nussear KE, Esque TC, Barber AM, Vittum KM, Medica PA, Tracy CR, Hunter

Emde, R. N., Plomin, R., Robinson, J., Corley, R., DeFries, J., Fulker, D. W., Reznick JS, Campos J, Kagan J, Zahn-Waxler, C. 1992. Temperament, emotion, and cognition at fourteen months: The MacArthur Longitudinal Twin Study. Child Development, 63(6): 1437-1455

Germano JM, Field KJ, Walsh A, Kahn P, Sheppard J, Swaisgood RR. 2012. Do differences in release area habitat features affect post-translocation movement? A case study on desert tortoises. Las Vegas (NV): Desert Tortoise Council 2012 Symposium

Germano JM, Nafus MG, Perry JA, Hall DB, Swaisgood RR (2017) Predicting translocation outcomes with personality for desert tortoises. Behavioral Ecology 28(4): 1075-1084.

Goldsmith, H.H, Buss, AH, Plomin R, Rothbart MK, Thomas A, Chess S, Hinde S, McCall RB. 1987. What is temperament? Four approaches. Child Development 58(2): 505-529

Groothuis, T.G. Carere C. 2005.Avian personalities: characterization and epigenesis. Neuroscience and Biobehavioural Reviews 29: 137-150

Jones B.R. 1977a. Sex and strain differences in the open-field responses of the domestic chick. Applied Animal Ethology 3: 255-261

Lagarde F, Guillon M, Dubroca L, Bonnet X, Ben Kaddour K, Slimani T, El Mouden HE. 2008. Slowness and acceleration: a new method to quantify the activity budget of chelonians. Animal Behavior 75: 319-329.

Livoreil B. 2009. Distribution of the Endangered Hermann's tortoise Testudo hermanni hermanniin Var, France, and recommendations for its conservation. Oryx The International Journal of Conservation 43 (2): 299-305

Martin LB, Fitzgerald L. 2005. A taste for novelty in invading house sparrows, Passer domesticus. Behavioral Ecology 16: 702-707 
Pelliteri-Rosa D, Sacchi R, Galeotti P, Marchesi M, Fasola M. 2010. Do Hermann's Tortoise (Testudo Hermanni) discriminate colours ? An experiment with natural and artificial stimuli. Italian Journal of Zoology 77: 481-491

Pille F, Caron S, Bonnet X, Deleuze S, Busson D, Girard F. 2017. Biodiversity and Conservation 27 (2): 437-457

Plomin R, Braungart, JM, Campos, JJ, Corley, RP, DeFries, J, Emde, RN, Fulker, D W, Kagan, J, Reznick, JS, Robinson, JL, Zahn-Waxler, C. 1993. Genetic change and continuity from fourteen to twenty months: The MacArthur Longitudinal Twin Study Society for Research in Child Development. Child Development 64: 1354-1376

Rodríguez A, Clergeau P. Hausberger M. 2010. Flexibility in the use of social information in the successful Sturnus vulgaris: experiments with decoys in different populations. Animal Behaviour 80:965-973

Rodriguez A. 2010. Behavioural mecanisms of biological invasions: flexibility and social facilitation in European straling, Sturnus vulgaris. PhD Thesis. University of Rennes 1

Sibeaux, A, Michel C, Bonnet X, Caron S, Fourniere K, Gagno S, Ballouard JM. 2016. Sexspecific ecophysiological responses to environmental fluctuations of free-ranging Hermann's tortoises: implication for conservation. Conservation Physiology 4 (1)

Sih A, Kats LB, Maurer EF. 2004. Behavioural correlations across situations and the evolution of antipredator behaviour in a sunfish-salamander system. Animal Behavior 65: 29-44

Sih A, Bell A, Johnson JC. 2004. Behavioral syndromes: an ecological and evolutionary overview. Trends in Ecology and Evolution 19: 372-378

Sinn D, Gosling S, Moltschaniwskyj N. 2008. Development of shy/bold behaviour in squid: context-specific phenotypes associated with developmental plasticity. Animal Behaviour 75: $433-442$

Sullivan BK, Nowak EM, Kwiatkowski MA. 2015. Problems with mitigation translocation of herpetofauna. Conserv Biol. 29:12-18.

Van Oers K, Drent P, Goede P, Van Noordwijk A. 2004a. Realized heritability and repeatability of risk-taking behaviour in relation to avian personalities. Proceedings of the Royal Society of London 271: 65-73 